\title{
Transmisi dan Transformasi Dakwah (Sebuah Kajian Living Hadis dalam Channel Youtube Nussa Official)
}

\section{Da'wah Transmission and Transformation (A Study of Living Hadith in the Nussa Official Youtube Channel)}

\author{
Ridha Hayati \\ Pascasarjana UIN Sunan Kalijaga Yogyakarta \\ Email:ridhahayati88@gmail.com \\ Artikel diterima 26 Maret 2020, diseleksi 26 Mei 2020, \\ dan di setujui 05 Juli 2020
}

Abstrak: Tulisan ini menyoroti tentang serial animasi islami yang belakangan ini banyak diminati anak-anak juga orang dewasa yaitu Nussa Rara (akronim dari Nusantara). Nussa Official adalah sebuah channel youtube yang berisi kartun animasi edutainment (educational entertainment), mengusung tema seputar keislaman yang bersumber dari al-Qur'an dan hadis. Wahyu dan pesan Nabi ditampilkan dengan unik dan mudah dipahami anakanak, berbeda dengan animasi pada umumnya yang bersifat global. Fokus penelitian ini adalah pada makna basmallah dalam channel youtube@ Nussa Official. Penelitian ini menggunakan pendekatan alanisis-deskriptif dengan dibantu teori sosiologi pengetahuan Karl Mannheim. Hasil kajian ini menunjukkan bahwa: Pertama, makna dari pembacaan basmallah adalah 1) Memohon perlindungan Allah dari setan, setan diyakini mengecil bagaikan lalat. 2) Rutinitas menjadi bernilai ibadah 3) Memperoleh keberkahan 4) Membangkitkan semangat dan membesarkan jiwa 5) Merasakan ketenangan. Kedua, kajian hadis mengalami perkembangan. Kajian hadis di masa Nabi hingga munculnya pensyarah belum melahirkan perbedaan yang signifikan, 
bertumpu pada teks dengan menggunakan media oral hingga tulisan. Hingga kemudian kajian hadis ini mengalami perkembangan, dengan lahir sebuah kajian living hadis yang bertitik tolak dari praktik (konteks). Seiring berkembangnya sosial kemasyarakatan, politik, ilmu pengetahuan dan teknologi yang semakin pesat kajian terhadap hadis meluas hingga ke media youtube. Ketiga, channel youtube @Nussa Official menunjukkan adanyaperkembangan pada media da'wah atau penyampaian hadis. Media penyampaian hadis masa Nabi dengan lisan, kemudian berkembangan melalui tulisan, lukisan, hingga pada media (youtube, instagram) dll. Hadirnya hadis yang terekam dalam channel youtube Nussa Official ini memberi nafas baru bagi kajian islam maupun hadis berbasis media. Dengan demikian membuktikan bahwa serial animasi ini mengalami transmisi dan transformasi.

Kata Kunci: Living Hadis, Dakwah, Youtube, Transmisi, Transformasi

Abstract: This paper highlights an Islamic acronym from the animated series that has recently attracted many kids and adults, Nussa Rara (an acronym from the archipelago). Nussa Official is a youtube channel that contains animated cartoon edutainment (educational entertainment), carrying themes around Islam originating from the Qur'an and Hadith. The Prophet's revelations and messages are displayed uniquely and easily understood by kids, unlike the animation in general, which is global. The focus of this research is on the meaning of basmallah in the Youtube channel @Nussa Official. This research uses a descriptive analysis approach with Karl Mannheim's knowledge sociology theory. The result of this study indicate that: First, the meaning of the basmallah reading are 1) Asking for God's protection from Satan, Satan is believed to shrink like a fly. 2)Making the routines became valuable worship 3) Obtaining blessing 4) Awakening the spirit and raising the soul 5) Feeling calm. Second, the study of hadith experiences development. The study of hadithin the Prophet time until the appearance of the Islamic preacher has not yet the significant difference, resting on the text by using oral media to writing. Until then this hadith study of living hadith that starts from the practice (context). As the development of social, political, scientific and technological, the rapid study of hadith extends to the youtube media. Third, the youtube channel of @Nussa Official shows developments in the media of da'wah or 
the hadith delivery. The hadith media delivery of the Prophet time was orally. Then develop through writing, painting, to the media (youtube, instagram) and others. The presence of the hadith recorded on the Nussa Official youtube channel gives a new breath to the study of Islam and media-based Hadith. Thus proving that this animated series underwent transmission and transformation Keywords: Living Hadith, Da'wah, Youtube, Transmission, Transformation

\section{A. Pendahuluan}

Peran youtube di Indonesia sebagai sarana publikasi konten terus meningkat bahkan mulai menggantikan kedudukan televisi. Berdasarkan hasil survei google dan kantar TNS, 92 persen pengguna Indonesia menyatakan youtube adalah tujuan pertama mereka ketika mencari konten video. ${ }^{1}$ Sebagian besar pengguna Indonesia berpendapat bahwa Youtube memudahkan mereka dalam mencari konten yang menarik dengan topik yang beragam. Secara umum konten youtube channel @ Nussa Official belakangan ini banyak menarik perhatian masyarakat. Channel @Nussa Official dikemas dalam bentuk serial animasi dengan mengangkat tema edutainment (educational entertainment), mendidik melalui hiburan. Selain itu animasi ini mengangkat nilai-nilai agama yang bersumber dari ajaran Nabi (hadis) yang kemudian dikemas dengan rapi sehingga mudah dimengerti oleh anak-anak. Berbeda dengan animasi pada umumnya yang sifatnya global.

Penelitian ini tergolong kajian living hadis. Kajian living hadis adalah kajian yang bertitik tolak dari praktik (konteks). Praktik yang terjadi di masyarakat yang diilhami oleh teks hadis. Fokus kajian living hadis adalah pada satu bentuk kajian atas fenomena praktik, tradisi, ritual atau perilaku yang hidup di masyarakat yang memiliki landasan berupa hadis Nabi. ${ }^{2}$ Berdasarkan hasil pengamatan penulis, kajian living hadis dari tahun 2013 hingga tahun 2017 masih seputar pada praktik dan ritual di masyarakat, belum ditemui kajian living hadis dalam media youtube. ${ }^{3}$ 
Hanya di tahun 2017 terdapat 1 kajian living hadis dalam televisi ${ }^{4}$ Oleh karena kekosongan tersebut penulis mengkaji kajian living hadis dalam via youtube. Hal ini menunjukkan bahwa kajian hadis maupun kajian keislaman sangat luas tidak hanya berkutat pada teks dan praktik saja, tetapi masuk dalam dunia digitalisasi khususnya media youtube. Media youtube merupakan salah satu konsep moderasi dakwah yang dinilai Mutaqin dapat memberi pesan damai ${ }^{5}$.

Penelitin ini berfokus pada tema basmallah dalam channel @Nussa Official. Peneliti, mencoba menggali teks atau rujukan yang ada dibalik adegan animasi tersebut dengan seperangkat ilmu living hadis. Maka dari itu permasalahan yang akan dijawab dalam penelitian ini adalah: 1. Bagaimana sejarah munculnya channel Nussa Official. 2. Bagaimana makna basmallah dalam Youtube Nussa Official. 2. Bagaimana transmisi dan transformasi basmallah itu sendiri.

\section{B. Metode Penelitian}

Adapun metode yang digunakan dalam penelitian ini adalah sebagai berikut:

\section{Jenis Penelitian}

Jenis penelitian ini merupakan penelitian kualitatif. Penelitian kualitatif adalah jenis penelitian yang menghasikan penemuan yang tidak dapat diperoleh dengan menggunakan prosedur statistik atau pengukuran. Penelitian kualitatif secara umum dapat digunakan untuk penelitian tentang kehidupan masyarakat, aktivitas sosial, sejarah, dan lainnya. Tujuan dari menggunakan metode ini adalah untuk memahami apa yang tersembunyi dibalik fenomena yang terkadang merupakan sesuatu yang sulit dipahami. ${ }^{6}$

\section{Sumber Data}

Sumber data yang digunakan dalam penelitian ini yaitu sumber data primer dan sumber data sekunder. Sumber data primernya adalah akun youtube youtube Nussa Official. Sedangkan sumber 
sekundernya yaitu seluruh literatur yang berkaitan dengan tema penelitian termasuk di dalamnya adalah buku, jurnal, software hadis dan lainnya.

\section{Teknik Pengumpulan Data}

Adapun langkah-langkahnya sebagai berikut: pertama, penulis memutar youtube Nussa Official dalam episode "Dahsyatnya Basmallah" juga episode-episode lain yang berkaitan dengan tema tersebut. Langkah kedua, penulis mulai membedah isi tayangan dengan memaknai maksud dari potongan dialog dan gambar yang dipilih, kemudian menggali makna teks hadis serta mencari rujukan teks yang digunakan. Langkah ketiga, menarik kesimpulan dari penelitian yang telah dilakukan. Data yang dipaparkan adalah dalam bentuk deskriptif.

\section{Analisis}

Penulis melihat bagaimana makna basmallah dalam tayangan tersebut dan menganalisis bagaimana proses transmisi dan transformasi dengan seperangkat pengetahuan yang ada.

\section{Profil Channel Nussa Official}

Kartun Nussa dan Rara pertama kali rilis di channel Nussa Official pada 20 November 2018. Kartun ini digagas oleh pemuda Indonesia bernama Mario Irwinsyah yang berkolaborasi dengan 4 Stripe Production. Kemudian digarap oleh studio animasi The Little Giants. Tokoh yang berkedudukan sebagai chief executive producers adalah Aditya Triantoro, chief finance officer Yuda Wirafianto, Chief Operation Officer Ricky MZC Manoppo dan ada tokoh lainnnya yang berperan dalam tayangan animasi ini. ${ }^{7}$ Masyarakat dapat bisa menikmatinya di channel youtube @Nussa Official. ${ }^{8}$

Serial animasi ini memiliki pesan moral dan nilai edukasi yang tinggi pada setiap episodenya. Kontennya memuat ajaran Islam baik yang bersumber dari al-Qur'an maupun hadis. Tayangan kartun ini berdurasi 
3 menit sampai 5 menit. ${ }^{9}$ Tayangan ini banyak mengambil perhatian baik dari kalangan anak-anak hingga orang dewasa. Terbukti dalam waktu 2 bulan dalam kolom komentar Youtube Nussa Official banyak yang memberi respon positif selain itu penonton tidak sabar menunggu tayangan berikutnya bahkan menduduki posisi trending 3 di Youtube Indonesia. Hingga kini channel Youtube Nussa Official mencapai 4 juta subcriber. Adanya Channel ini diawali dengan sebuah kegelisahan para orang tua akan tontonan anak-anak yang minim akan nilai-nilai kebaikan dan nilai-nilai yang mendidik. ${ }^{10}$

Dari kelucuan kartun ini ada dua bocah lucu dibaliknya yaitu Muzzaki Ramdhan sebagai pengisi suara Nussa dan Aysha Ocean Fajar pengisi suara Rara. Animasi ini menggunakan simbol-simbol agama seperti kopiah dan jilbab. Sosok Nussa digambarkan sebagai seorang anak lakilaki yang berpakaian gamis lengkap dengan kopiah putih. Karakter Nussa diciptakan sebagai tokoh penyandang disabilitas. Hal tersebut tampak pada kaki kirinya yang menggunakan kaki palsu. Makna dibalik kaki palsu ini adalah ingin menunjukkan bahwa kekurangan bukanlah sebuah penghalang untuk mencapai impian dan kesempurnaan. Sedangkan karakter Rara, digambarkan sebagai adik kandung Nussa yang cantik berusia 5 tahun dengan menggunakan gamis dan jilbab dengan memiliki karakter yang ceria.

\section{Basmallah dalam Channel Nussa Official}

Pada tayangan Nussa Official, episode yang membahas basmalllah adalah pada episode yang berjudul "Dahsyatnya Basmallah". Episode lain yang berkaitan dengan basmallahterdapat pada episode yang berjudul "Adab Makan" dan "Adab Tidur"

\section{Dahsyatnya Basmallah}




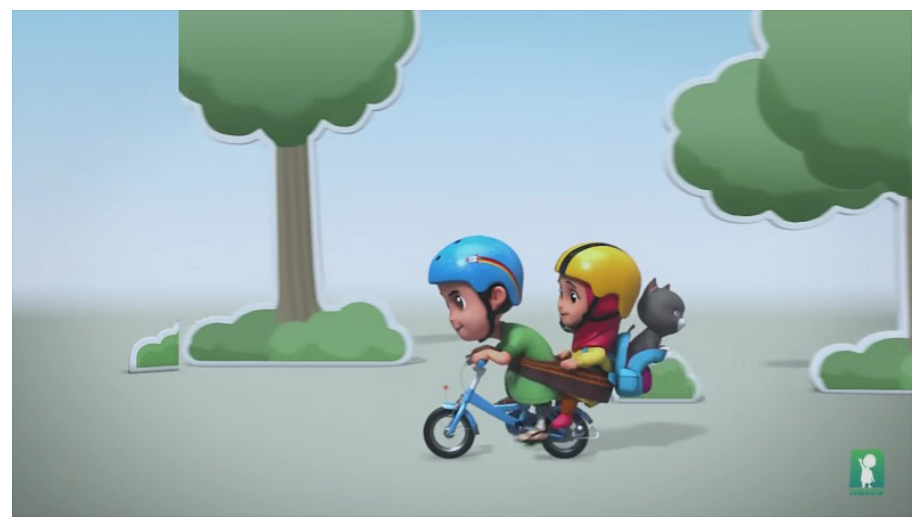

Tayangan ini berawal dari Nussa, Rara, dan Anta yangingin pergi. Mereka mengendarai 1 sepeda dengan segala keamanan yang telah dipersiapkan. Namun di tengah perjalanan Anta (seekor kucing peliharaan Nussa dan Rara) diganggu oleh setan. Ketika itu posisi Anta adalah di dalam tas Rara. Setan pun terus mengganggu Anta hingga kemudian Anta melakukan perlawanan terhadap setan. Namun, karena Anta bergerak-gerak seakan ingin lompat maka Rara pun ikut bergerak sampai membuat Nussa hilang keseimbangan dan akhirnya mereka bertiga jatuh dari sepeda.

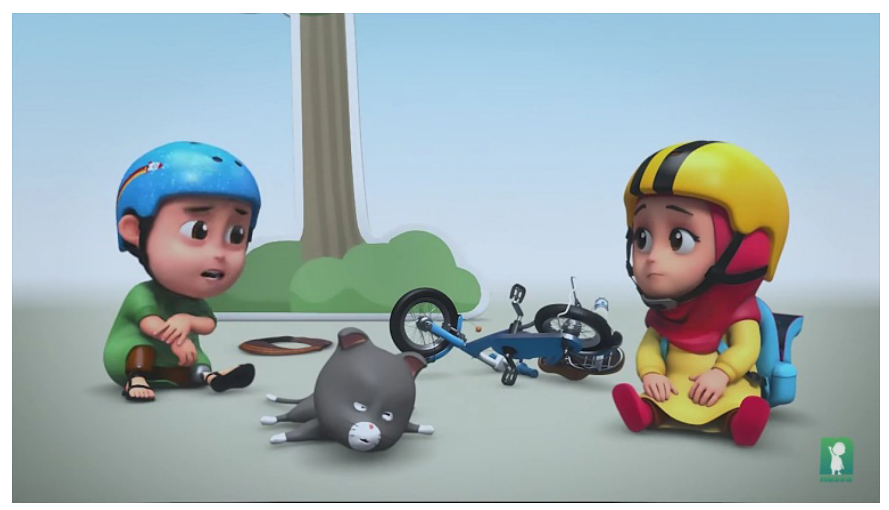

Setelah jatuh dari sepeda Rara mengeluh dan menyalahkan Nussa karena naik sepeda dengan cepat. Setelah Rara mengatakan hal tersebut setan yang tadi mengganggu, tertawa bahagia dan berubah wujudnya semakin besar. 


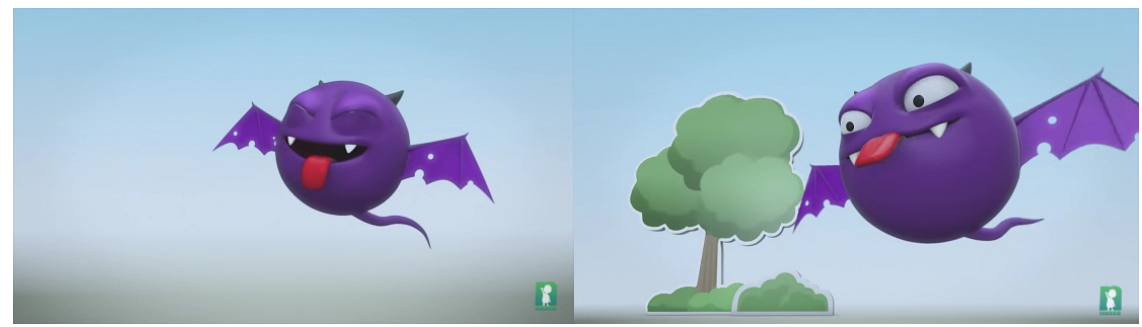

Mengapa setan semakin membesar?

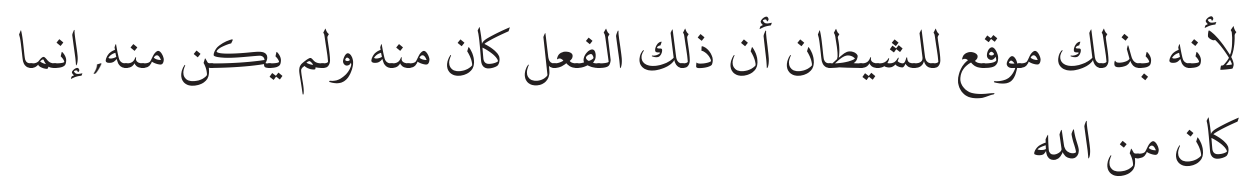

Karena dengan ucapan tersebut membuat setan bangga, sebab ia menyangka kecelakaan itu disebabkan pada Nussa yang mengendarai dengan cepat. Hal ini sejatinya dari Allah, maka Nabi memerintahkan untuk mengganti dengan ucapan Bismillah. Sehingga setan tidak menganggap darinya dan dirinya tidak memiliki peran apapun.

Setelah itu Anta langsung memberitahu bahwa sebelum berangkat belum membaca basmallah. Tidak menunggu waktu lama merekapun membaca basmallah bersama-sama. Kemudian, setan yang tadinya besar tiba-tiba "mengecil seperti lalat lalu hinggap dihidung Anta dan Anta terlihat lebih besar dari pada lalat".

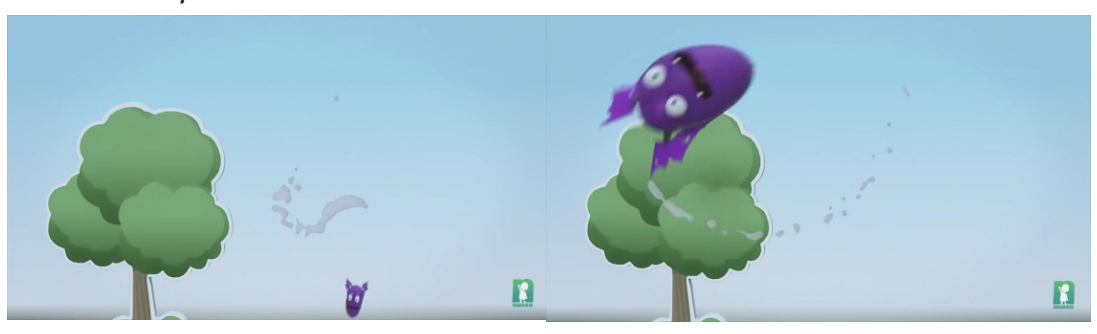

Hal tersebut sebagaimana hadis Nabi:

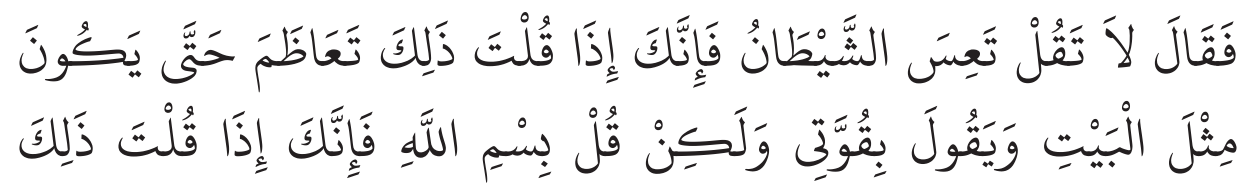




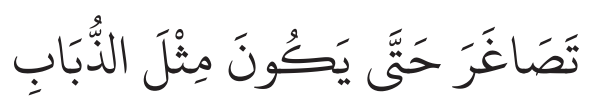

Jangan kamu mengucapkan celakalah setan, karena ketika kamu mengucapkan seperti itu maka syetan akan membesar sebesar rumah dengan sombongnya syetan akan berkata: itu terjadi karena kekuatanku. Akan tetapi ucapkanlah "Bismillah" sebab jika engkau mengucapkan basmallah syetan akan mengecil hingga seukuran lalat.

\section{Adab Makan}

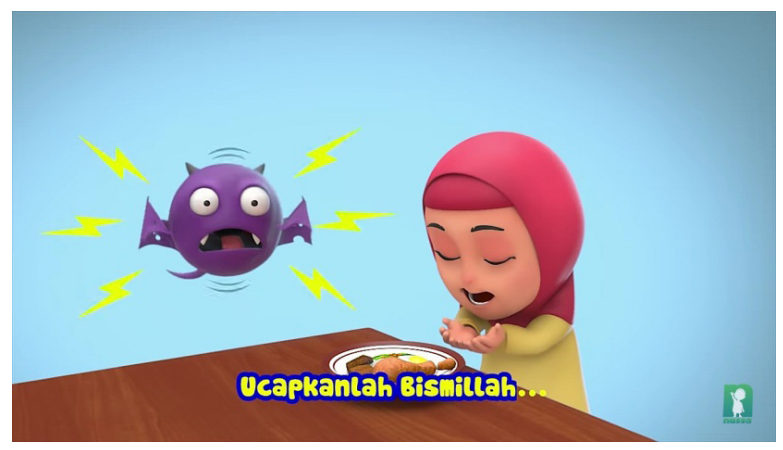

Pada episode ini tayangan yang ditampilkan adalah berupa adegan lagu yang isinya mengajarkan bagaimana adab-adab sebelum makan. Fokus penulis pada episode ini adalah pada bagian basmallah. Tampak dalam adegan tersebut setan mengecil setelah membaca basmallah. Adapun isi lagu tersebut adalah:

Makan jangan asal makan perut buncit langsung kenyang

Makan pakai aturan yang Nabi ajarkan

Makan jangan asal makan perut buncit langsung kenyang

Raihkah keberkahan dalam setiap makan..Lets go 3x

Cuci bersih tanganmu

Ucapkanlah bismillah

Gunakan tangan kananmu

Biasakan tak berdiri 
jangan tiup yang panas

lebih baik dikipas

minum dalam tiga tegukan

satu, dua, tiga..

\section{Adab Tidur}

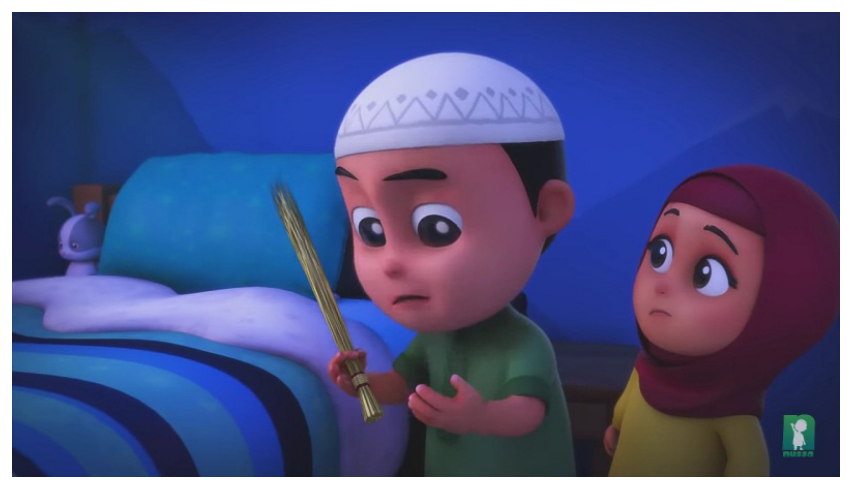

Pada episode ini menampilkan bagaimana adab sebelum tidur. Dijumpai hal yang sama ketika usai membaca basmallah dan menyapukan tempat tidur setan diilustrasikan menjadi kecil terbang dan kabur bagai lalat.

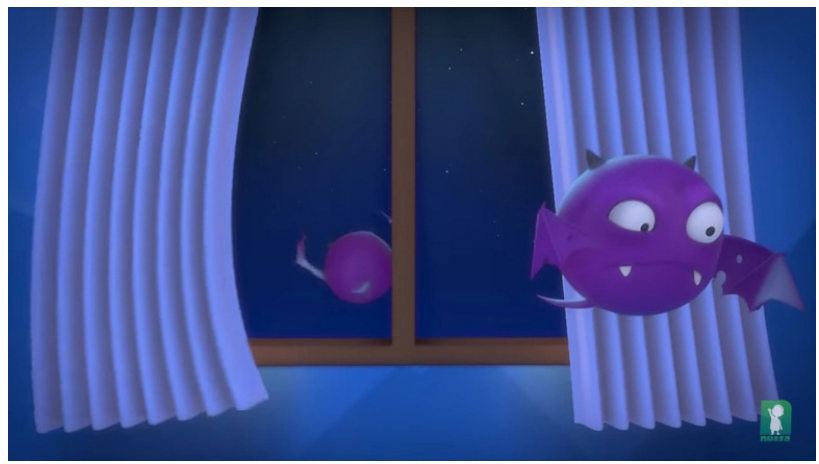

Adapun adab-adab tidur sebagai berikut: membaca basmallah sebelum menyapu tempat tidur, wudhu, baca ayat kursi, tiga surah Qul (Alikhlas, al-Falaq, an-Nas) masing-masing 3 kali lalu ditiupkan ketangan kemudian diusap ke muka dan ke badan, tidur menghadap ke kanan atau arah kiblat, baca do'a tidur. 


\section{E. Makna Basmallah}

Dalam sebuah hadis sahih yang diriwayatkan olleh Abu Dawud dari Walid Abu Malih, ayahnya yang pernah dibonceng Rasulullah menceritakan:

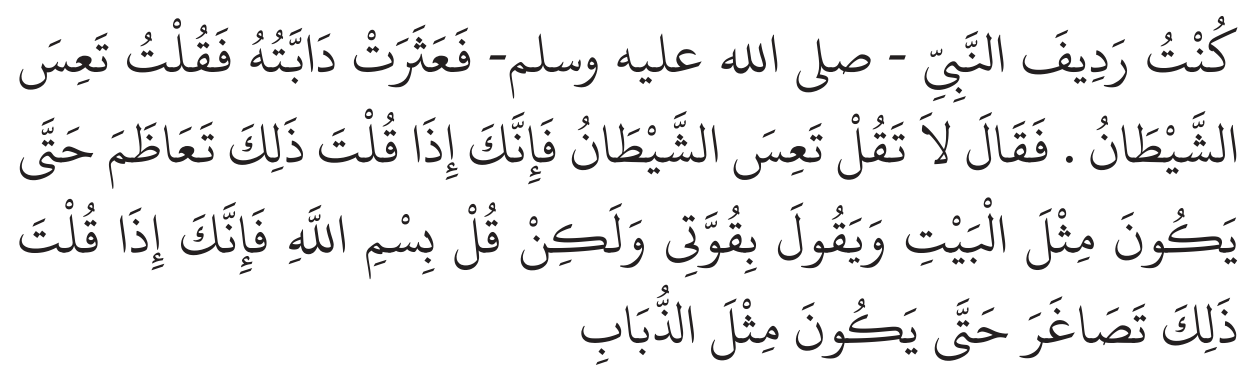

Ketika aku dibonceng Nabi SAW tiba-tiba unta beliau tergelincir. Serta merta aku mengatakan, Celakalah syetan, sebab jika kamu katakan seperti itu maka syetan akan membesar sebesar rumah dengan sombongnya syetan akan berkata: itu terjadi karena kekuatanku. Akan tetapi ucapkanlah "Bismillah" sebab jika engkau mengucapkan basmallah syetan akan mengecil hingga seukuran lalat. "(HR. Abu Dawud).

Hadis lain tentang basmallah,

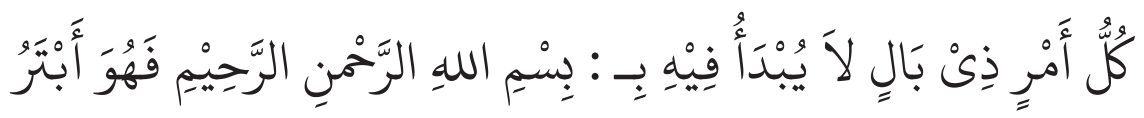

"Setiap perkara penting yang tidak dimulai dengan bismillahirrahmanirrahim, amalan tersebut terputus berkahnya. (HR. alKhatib dalam al-Jami')

Serial animasi ini meski tidak disebutkan dalam adegan secara langsung, terlihat menggunakan hadis yang pertama. Hadis kedua tidak terlalu terlihat dirujuk. Meski tidak secara langsung mengacu pada hadis kedua tayangan pada episode berikutnya pada adab makan dan adab tidur mereka juga mempraktikkan bacaan basmallah. Artinya pada setiap perkara menerapkan pembacaan basmallah. Maka secara ekplisit tayangan ini hanya menggunakan hadis yang berkualitas sahih yaitu 
hadis yang diriwayatkan oleh Abu Dawud. Sedangkan secara implisit hemat penulis tayangan ini juga menggunakan landasan hadis yang kedua yang sebagian ulama mengatakan status hadis ini dhaif.

Imam at-Thahawi menjelaskan hadis ini ${ }^{11}$

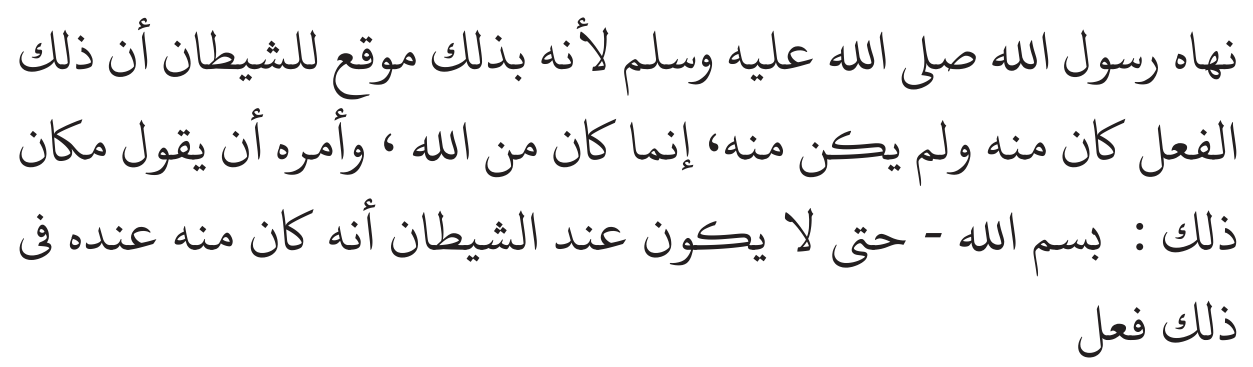

"Rasulullah melarang hal itu karena ucapan tersebut akan membuat setan bangga, dia menyangka kecelakaan itu terjadi disebabkan diri setan, padahal sejatinya bukan. Namun datang dari Allah dan Nabi sawmemerintahkan untuk menggantinya dengan ucapan Bismillah.. sehingga setan tidak menganggap bahwa kecelakaan itu darinya dan peran atasnya."

Ibnu Katsir menjelaskan hadis tersebut (setan yang mengecil) adalah akibat pengaruh dari keberkahan Bismillah, oleh karenanya dianjurkan untuk membacanya di awal setiap perkataan dan perbuatan. ${ }^{12}$ Secara umum membaca basmallah (bismillahirrahmanirrahim) dan tasmiyah (bismillah saja) dianjurkan pada setiap awal amal kebajikan sebagaimana riwayat sahih tentang menjima' istri, naik kendaraan, memulai makan, dan lainnya. Terdapat sebuah riwayat: "setiap urusan dalam kehidupan yang di dalamnya tidak dimulai dengan bismillahirrahmanirrahim maka terputus. "(diriwayatkan oleh As-Subki dalam Thabaqat As-Syafi'iyah, $1 / 6)$.

Sedangkan menurut ustadz Abdul Somad yang dijelaskan dalam akun resmi Chanel Youtube Nussa Official bahwa ketika membaca bismillah, setan benar akan menjadi kecil dan manusia menjadi besar. Namun hal ini bukan terjadi pada fisiknya melainkan pada mental kita sebagai muslim. Dengan mengucapkan basmallah maka tidak ada keburukan 
kepada kita di bumi maupun di langit. Sehingga hal ini akan membuat setan menciut sebab takut akan kebesaran Allah. ${ }^{13}$

Mengulas kembali tayangan tersebut, adegan setan digambarkan "mengecil fisiknya" setelah dibacakan basmallah. Hal ini merupakan pembacaan yang tekstual. Di mana teks dibaca atau diilustrasikan sama seperti bunyi teks yang ada. Jika membaca dari kaca mata kajian hadis, dalam memahami hadis penting untuk melihat pada aspek historishadis baik dari asbabul wurud hadis, posisi Nabi ketika menuturkan hadis, kepada siapa dan dalam konteks yang bagaimana hadis tersebut dituturkan. Jadi, mengenai diibaratkan lalat? karena kronologis sebelumnya bagi masyarakat Arab, pada masa itu siapa yang dihinggapi lalat ia sial.

Selanjutnya, membaca sang kreator dan produsen dari kaca mata Gadamer maka pembacaan hadis yang demikian tidak terlepas dari prapemahaman diri seseorang tersebutbaik dari pendidikan, latar belakang sosial, tradisi, lingkungan sekitar ia hidup dan lainnya. ${ }^{14}$ Salah satu tokoh dibalik Nussa dan Rara yang berposisi sebagai executive producers yaitu Aditya Triantoro. Aditya mengaku baru-baru berhijrah dan mendapatkan petunjuk ketika akan atau sebelum membangun proyek Nussa Official ini. Aditya merupakan seseorang yang ahli dalam animasi dapat dilacak pendidikan yang didalaminya seputar animasi, bukan seorang yang menekuni keilmuan hadis. Maka tidak diherankan jika hasil karyanya juga mengikuti keilmuan yang ditekuninya. Fokus producer adalah bukan pada bagaimana memahamkan hadis dengan pembacaan yang tekstual maupun kontekstual tetapi pada pesan yang ingin disampaikan melalui animasi.

Terlepas dari hal tersebut tayangan serial animasi ini telah mampu menyampaikan ajaran Nabi (hadis) dengan menghadirkan ilustrasi yang menarik bagi anak-anak dan mudah dipahami. Wujud setan dibuat dengan penampakan yang jelek dan lucu akan membuat anak-anak tertawa. Kemudian, isi hadis yang ketika itu Nabi sedang "mengendarai unta" dalam adegan Nussa dan Rara digambarkan sesuai konteks 
sekarang dimana peran unta diganti dengan sepeda. Hal ini yang membuat anak-anak semakin tertarik untuk menonton.

Melihat praktik basmallah dalam animasi Nussa dan Rara memiliki makna. Meminjam teori Karl Mannheim, beliau menyatakan bahwa tindakan manusia dibentuk dari dua dimensi yaitu perilaku (behavior) dan makna (meaning). Sehingga, dalam memahami suatu tindakan seorang ilmuan harus mengkaji perilaku eksternal dan makna perilaku. Mannheim mengklasifikasikan dan membedakan makna perilaku dari suatu tindakan sosial menjadi tiga macam makna yaitu 1) makna objektif, adalah makna yang ditentukan oleh konteks sosial di mana tindakan berlangsung. 2) makna ekspresive, adalah makna yang ditunjukkan oleh aktor (pelaku tindakan). 3) makna dokumenter, yaitu makna yang tersirat atau tersembunyi, sehingga aktor tersebut tidak sepenuhnya menyadari bahwa suatu aspek yang diekspresikan menunjukkan kepada kebudayaan secara keseluruhan. ${ }^{15}$

Terdapat beberapa makna membaca basmallah dalam animasi Nussa dan Rara yaitu : Pertama, agar setan mengecil seperti lalat. Hal ini dapat diperhatikan pada episode dahsyatnya basmallah, adab makan, dan adab tidur. Ketiga episode dijumpai hal yang sama ketika usai membaca basmallah setan diilustrasikan menjadi kecil terbang dan kabur bagai lalat. Hal ini menandakan bahwa makna dari membaca basmallah adalah memohon perlindungan Allah dari setan dan membuat setan mengecil bagaikan lalat. Makna kedua yaitu, menjadikan rutinitas sebagai ibadah. Hal ini dapat dilihat ketika melakukan aktivitaas berkendara, makan, minum, tidur dan lainnya yang dimulai dengan membaca basmallah akan bernilai ibadah dibandingkan dengan aktivitas yang tidak dimulai dengan basmallah.Makna ketiga, sebuah pengharapan agar memperoleh keberkahan. Dengan membaca basmallah pada setiap memulai perkara akan memperoleh keberkahan karena segala sesuatu telah disandarkan pada Allah. Makna keempat, membangkitkan semangat dan membesarkan jiwa. Ketika yakin akan tahayul, jin, dan lainnya manusia akan merasa down. Tetapi ketika diserahkan pada Allah maka kita (jiwa) 
nya akan besar . Makna kelima, memberikan ketenangan. Hal ini karena seluruhnya telah diserahkan pada Allah yang maha besar, maka segala masalah akan terlihat kecil.

\section{F. Transmisi dan Transformasi}

Berbicara mengenai pembahasan transmisi dan transformasi sangat penting dalam kajian ini. Keberadaan literatur hadis sebelum koleksi kanonik hadis adalah masalah yang kontroversi. Golziher secara eksplisit menyatakan bahwa pada awalnya hadis tidak secara eksklusif dimaksudkan untuk ditransmisikan secara lisan dan memberikan bukti bahwa ia juga telah ditulis secara sporadis pada tahap yang sangat awal. ${ }^{16}$ Namun, dalam pembacaan sebuah tradisi yang berlandaskan pada teks sangat penting untuk melihat transmisi dan transformasi teks tersebut, dari mana sumber pertama/teks tersebut lahir hingga kemudian teks tersebut dijadikan oleh masyarakat sebagai living hadis (hadis yang hidup). Dengan demikian dapat terlihat apakah teks tersebut mengalami perkembangan dan perubahan pada setiap masanya.

Transmisi dan transformasi tidak terlepas dari sebuah ruang dan waktu. Menurut Irwan Abdullah kebudayaan menjadi suatu yang tidak hanya mampu menjelaskan realitas kehidupan tetapi kebudayaan menjadi unsur utama dalam proses pembangunan diri manusia dan masyarakat terdapat tiga proses di mana kebudayaan mengambil tempat yang sangat penting. Pertama, kebudayaan merupakan sebuah faktor penting di dalam mendorong proses transformasi. Kedua, kebudayaan dinilai sebagai penghambat proses transformasi karena nilai yang dikandungnya tidak sesuai dan bertentangan dengan nilai dan praktik kehidupan baru. Ketiga, kebudayaan harus dilihat sebagai produk dari suatu proses transformasi di mana ia diproduksi dan direproduksi dalam kehidupan sehari-hari. ${ }^{17}$

Transformasi masyarakat menurut Irwan Abdullah mengandung tiga agenda. Pertama, transformasi bersifat analitis. Sifat ini mengacu pada kualitas abstrak mengenai struktur sosial dan proses perubahannya. Secara analitis proses ini bersifat universal baik dari segi ruang dan waktu. 
Dalam hal ini transformasi mengandung pengertian adanya peningkatan kompleksitas sosial suatu masyarakat. kedua, bersifat historis. Proses ini memperlihatkan periode waktu tertentu yang dalam satuan waktu tersebut dapat ciri-ciri baru di dalam suatu masyarakat. Ketiga, sifat praktis dari transformasi serangkaian kebijakan dirumuskan untuk membangun kompleksitas masyarakat. Dalam ketiga orientasi ini kebudayaan dapat ditempatkan pada posisi yang berbeda.

Meninjau serial animasi NussaRara yang menyampaikan hadis melalui cara yang unik (kekinian) lewat youtube channel mengalami perkembangan dan perubahandari konteks awal masa Nabi. Proses awal Nabi menyampaikan hadis mulai dari lisan. kemudian berlanjut pada tulisan, lukisan, hingga pada media sosial. Pertama, lisan. Sesuatu yang tergolong dalam bentuk ini adalah ceramah, kuliah, diskusi, dan lainnya yang dilakukan dengan lidah dan bersuara. Kedua, tulisan. Seperti buku, jurnal dan lainnya. Ketiga, Lukisan seperti kaligrafi. Keempat, media. Bentuk ini dapat berupa televisi, youtube. Channel Nussa dan Rara yang lahir dizaman sekarang memiliki posisi sebagai penyampai hadis pada kategori terakhir yaitu media sosial berbasis youtube dalam bentuk animasi. Ini membuktikan bahwa telah terjadi perubahan baik dari ruang, waktu, konteks, budaya di masing-masing zamannya.

Demikian kajian dalam hadis mengalami perkembangan, awalnya bertumpu pada kajian teks, baik sanad maupun matan hingga masuk pada praktik teks di masyarakat. Pemahaman hadis masa Nabi hingga munculnya pensyarah hadis belum melahirkan perbedaan yang signifikan yang bertumpu pada teks dengan menggunakan media oral hingga tulisan. Hingga kemudian kajian hadis mengalami perkembangan, lahir sebuah kajian Living Hadis yang bertitik tolak dari praktik (konteks). Pada awal tahun 2000 kajian living hadis ini belum ditemui. ${ }^{18}$ Kajian yang tersedia atas hadis ketika itu hanya terkait ilmu hadis dan pemaknaannya saja. Kajian living hadis ini banyak diminati khususnya oleh kalangan akademisi. Bahkan telah menyebar dalam berbagai rangkaian kegiatan seperti seminar, workshop maupun pelatihan-pelatihan khusus. Seiring 
berkembangnya sosial kemasyarakatan, politik, ilmu pengetahuan dan teknologi yang semakin pesat kajian terhadap hadis meluas ke media youtube (banyak diminati para milenial) sebagaimana dalam channel youtube Nussa Official. Hadirnya channel youtube Nussa Official ini memberi nafas baru bagi living hadis berbasis digital. Dengan demikian membuktikan bahwa serial animasi ini mengalami transmisi dan transformasi.

\section{G. Kesimpulan}

Dari penjelasan yang telah penulis paparkan sebelumnya, maka terdapat tiga poin kesimpulan, yaitu sebagai berikut:

1. Lahirnya Nussa Official diawali dengan sebuah kegelisahan para orang tua akan tontonan anak-anak yang minim akan nilai-nilai kebaikan dan nilai-nilai yang mendidik. Secara sadar ataupun tidakadeganyang ditampilkandalam animasi ini menggambarkan ajaran Islam yang sumbernya diambil dari hadis Nabi. Secara eksplisit hadis yang dirujuk dalam tema basmallah adalah hadis yang kualitasnya shahih. Secara implisitjuga merujuk pada hadis yang kualitasnya dhaif.

2. Makna membaca basmallah yang terdapat dalam animasi Nussa dan Rara adalah: Pertama, agar setan mengecil seperti lalat. Hal ini dapat diperhatikan pada episode dahsyatnya basmallah, adab makan, dan adab tidur. Ketiga episode dijumpai hal yang sama ketika usai membaca basmallahsetan diilustrasikan menjadi kecil terbang dan kabur bagai lalat. Hal ini menandakan bahwa makna dari membaca basmallah adalah memohon perlindungan Allah dari setan dan membuat setan mengecil bagaikan lalat. Makna kedua yaitu, menjadikan rutinitas sebagai ibadah. Hal ini dapat dilihat ketika melakukan aktivitaas berkendara, makan, minum, tidur dan lainnya yang dimulai dengan membaca basmallah akan bernilai ibadah dibandingkan dengan aktivitas yang tidak dimulai dengan basmallah.Makna ketiga, sebuah pengharapan 
agar memperoleh keberkahan. Dengan membaca basmallah pada setiap memulai perkara akan memperoleh keberkahan karena segala sesuatu telah disandarkan pada Allah. Makna keempat, membangkitkan semangat dan membesarkan jiwa. Ketika yakin akan tahayul, jin, dan lainnya manusia akan merasa down. Tetapi ketika diserahkan pada Allah maka kita (jiwa) nya akan besar. Makna kelima, memberikan ketenangan. Hal ini karena seluruhnya telah diserahkan pada Allah yang maha besar, maka segala masalah akan terlihat kecil.

3. Animasi Nussadan Raramenunjukkan adanya perubahan pada media menyampaikan (dakwah) berupa hadis dan kajian dalam hadis itu sendiri.Penyampaian hadis mengalami perubahan konteks dari awal masa Nabi. Masa Nabi proses menyampaikan hadis dimulai dari lisan. Kemudian berlanjut pada tulisan, lukisan, hingga pada media sosial. Demikian halnya pada kajian hadis, pada awalnya kajian hadis bertumpu pada teks, baik sanad maupun matan. Pemahaman hadis masa Nabi hingga munculnya pensyarah hadis belum melahirkan perbedaan yang signifikan yang bertumpu pada teks dengan menggunakan media oral hingga tulisan. Hingga kemudian kajian hadis mengalami perkembangan, yakni lahir sebuah kajian living hadis yang bertitik tolak dari praktik (konteks). Pada awal tahun 2000 kajian yang tersedia atas hadis hanya terkait erat dengan ilmu hadis dan pemaknaannya saja. Seiring berkembangnya sosial kemasyarakatan, politik, ilmu pengetahuan dan teknologi yang semakin pesat kajian terhadap hadis ini telah menjalar ke media youtube (banyak diminati para milenial) sebagaimana dalam channel youtube Nussa Official. Hadirnya channel youtube Nussa Official ini memberi nafas baru bagi living hadis berbasis digital. Dengan demikian membuktikan bahwa serial animasi ini mengalami transmisi dan transformasi. 


\section{Daftar Pustaka}

Abdullah, Irwan. "Tantangan Pembangunan Ekonomi dan Transformasi Sosial”, jurnal Humaniora Vol. Xiv No. 3/2002.

Ahmad bin Muhammad. Syarah Musykil al-Atsar. Muassasah ar-Risalah, 2006.

Al-Fatih Suryadilaga, Muhammad. "Living Hadis dalam Tradisi Sekar Makam", Jurnal al-Risalah, Vol. 13, No. 1, mei 2013.

Mutaqin AlZamzami, Konsep Moderasi Dakwah dalam M.Quraish Shihab Official Website, Jurnal Bimas Islam Vol 12 No.1, 2019.

Bakker. Anton. Metode Penelitian Filsafat. Yogyakarta: Kanisius, 1992.

Boum, George. Agama dalam bayang-bayang Relativisme: Agama, kebenaran dan Sosiologi pengetahuan, terj. Achmad Murtajib Chaeridan masyhuri Arow. Yogyakarta: PT. Tiara WacanaYogya, 1999.

Gadamer, Hans-Georg. Kebenaran dan Metode. terj. Ahmad Sahidah, Yogyakarta: Pustaka Pelajar, 2004.

Hayati, Ridha. “Moralitas Pemimpin: Dialektika atas Teks Suci Agama dan Pembentukan Budaya Lokal (Kajian Living Hadis dalam Sinetron Para Pencari Tuhan (PPT) Jilid 2 Eps.3)", Jurnal Lektur Keagamaan, Vol. 115, No. 2, 2017.

Ibnu Katsir, Tafsir al-Qur'an al-Azhim, Beirut: Dar al-Hadis, jild 1.

J. Maleong, Lexy. Metode Penelitian Kualitatif. Bandung: PT. Remaja Rosdakarya, 2010.

Saifuddin Zuhri dan Subkhani Kusuma Dewi Living Hadis Praktik, Resepsi. Teks, dan Transmisi, Yogyakarta: Q-Media, 2018.

Schoeler, Gregor. The Oral and The Written in Early Islam. London: 
Routledge Taylor D Francis Group, 2006.

Zuhri, Saifuddin. “Tradisi Puasa Senin kamis di Kampung Pekaten, Kota Gede, Yogyakarta" Proceeding Annual Conference for Muslim Scholars (ANCOMS), 2017.

Saeful Rahmat Pupu, "Penelitian Kualitatif, Jurnal Equilbrium", Vol. 5, No. 9, Januari-Juni 2009

Syamsuddin, Sahiron. Hermeneutika dan Pengembangan Ulumul Qur'an.

Yogjakarta: Pesantren Nasewea, 2009.

Channel Youtube @Nussa Official

Sumber Internet

http://artikula.id/alfatih/living-hadis-sebagai-sarana-kajian-living-hadisberkembang-di-era-kekinian/

Http://www.thelittlegiantz.com/ourcrew.html

Brilio.net. diposting 18 Maret 2019 pukul 19:35

https://www.nussaofficial.com/

http://youtu.be/ROUxf_VItdc 


\section{Endnotes}

1. Diposting 30 May 2018, https://www.trentech.id/fakta-perkembanganyoutube-di-indonesia/

2. Saifuddin Zuhri dan Subkhani Kusuma Dewi, Living Hadis Praktik, Resepsi. Teks, dan Transmisi, ( Yogyakarta: Q-Media, 2018), hlm. 8.

3. Diantaranya penelitian yang dilakukan oleh Muhammad al-Fatih Suryadilaga, "Living Hadis dalam Tradisi Sekar Makam”, Jurnal al-Risalah, Vol. 13, No. 1, mei 2013. Dan Saifuddin Zuhri, Tradisi Puasa Senin kamis di Kampung Pekaten, Kota Gede, Yogyakarta, Proceeding Annual Conference for Muslim Scholars (ANCOMS), 2017.

4. Ridha Hayati, Moralitas Pemimpin: Dialektika atas Teks Suci Agama dan Pembentukan Budaya Lokal (Kajian Living Hadis dalam Sinetron Para Pencari Tuhan (PPT) Jilid 2 Eps.3), Jurnal Lektur Keagamaan, Vol. 115, No. 2, 2017.

5. Mutaqin Al-Zamzami, Konsep Moderasi Dakwah dalam M.Quraish Shihab Official Website, Jurnal Bimas Islam Vol 12 No.1, 2019.

6. Pupu Saeful Rahmat, Penelitian Kualitatif, Jurnal Equilbrium, Vol. 5, No. 9, Januari-Juni 2009, hlm 2.

7. http://www.thelittlegiantz.com/ourcrew.html

8. Channel Youtube @Nussa Official

9. Brilio.net. diposting 18 Maret 2019 pukul 19:35

10. https://www.Nussaofficial.com/

11. Ahmad bin Muhammad, Syarah Musykil al-Atsar, Muassasah ar-Risalah, $20061 / 34$.

12. Ibnu Katsir, Tafsir al-Qur'an al-Azhim, (Beirut: Dar al-Hadis ), jild 1 hlm, 120.

13. http://youtu.be/ROUxf_VItdc

14. Sahiron Syamsuddin, Hermeneutika dan Pengembangan Ulumul Qur'an,. 
(Yogyakarta: Pesantren Nasewea, 2009), hlm.44-52. Lihat juga pada Hans-Georg Gadamer, Kebenaran dan Metode terj. Ahmad Sahidah, (Yogyakarta: Pustaka Pelajar, 2004), hlm. 573-592.

15. George Boum, Agama dalam bayang-bayang Relativisme: Agama, kebenaran dan Sosiologi pengetahuan, terj. Achmad Murtajib Chaeri dan masyhuri Arow (Yogyakarta: PT. Tiara Wacana Yogya, 1999), hlm. 18.

16. Gregor Schoeler, The Oral and The Written in Early Islam, (London: Routledge Taylor D Francis Group, 2006), hlm. 30.

17. Irwan Abdullah, TAntangan Pembangunan Ekonomi dan Transformasi Sosial, jurnal Humaniora Vol. Xiv No. 3/2002. Hlm. 261

18. http://artikula.id/alfatih/living-hadis-sebagai-sarana-kajian-living-hadisberkembang-di-era-kekinian/ 